\title{
Success Factors and Performance Indicators for Enterprise Application Integration
}

\author{
Alexander Schwinn \\ University of St. Gallen \\ Institute of Information Management \\ Mueller-Friedberg-Str. 8, \\ 9000 St. Gallen, Switzerland \\ alexander.schwinn@unisg.ch
}

\author{
Robert Winter \\ University of St. Gallen \\ Institute of Information Management \\ Mueller-Friedberg-Str. 8 \\ 9000 St. Gallen, Switzerland \\ robert.winter@unisg.ch
}

\begin{abstract}
The effectiveness and efficiency of information systems are closely related to the degree of integration between applications. In order to support the management of application integration, five success factors are analyzed. For each success factor, appropriate performance indicators are proposed. Since the analysis indicates that the success factors are closely interrelated, these dependencies are discussed and hypotheses are derived.
\end{abstract}

\section{Keywords}

Enterprise Application Integration, EAI, Enterprise Architecture Management, IT Controlling

\section{INTRODUCTION}

Design and management issues of information systems architecture (IS architecture) are discussed from a practitioner perspective (e.g. by Zachman, 1987) as well as from a scientific perspective (e.g. by Krcmar, 1990; Österle, Brenner and Hilbers, 1992). Architecture models help to understand and communicate enterprise architecture. They also support architecture design decisions.

Recently, some approaches integrate IS architecture design and management with other architectures in an enterprise (e.g. McDavid, 1999; Youngs, Redmond-Pyle, Spass and Kahan, 1999; Malhotra, 1996; Martin and Robertson, 2000). Some of these approaches focus on technologies, while others connect IS architecture to business requirements. Being one specific component of IS architecture, this paper addresses application architecture. A company's application architecture describes applications (or application domains) and their relations (or interfaces) on a conceptual level (Winter, 2003a). Application architecture is designed and managed from a business point of view. Design and management of application architecture aim at minimizing (development time as well as run-time) integration costs.

In this paper we propose success factors for application integration. For each success factor, appropriate performance indicators are proposed. After this introduction, conceptual considerations on the optimal level of application integration are used to identify general success factors (Section 2). A broad literature review helps to identify specific success factors for application integration in Section 3. For every success factor, respective performance indicators are proposed. As some of the success factors seem to be closely interrelated, their interdependencies are examined qualitatively in Section 4. This analysis results in a set of hypotheses for successful application integration which have to be validated quantitatively in further research.

\section{APPLICATION INTEGRATION}

In contrast to their technical interpretation as a container of software artifacts (e.g. modules and / or data structures), applications represent tightly interrelated aggregates of business system artifacts (e.g. business processes, business objects) from a business perspective. While tight couplings between business system artifacts lead to their aggregation into the same application construct, loose couplings are represented by interfaces between applications. The number of application constructs depends on the definition of 'tight coupling'. If a small number of (monolithic) applications are created in application design, only a few interfaces have to be implemented. As a consequence, costs for running and maintaining interfaces are low, while the total costs for running and maintaining applications are high due to more difficult change management and higher complexity. If many small applications are created in application design, much more interfaces are 
needed which imply higher operations and maintenance costs. On the other hand, the total application development and maintenance costs are significantly lower due to less application complexity. The question is how to find an optimal balance between the number of interfaces and the number of applications in order to reduce the total costs of operations and maintenance. These comprise (1) costs for developing and maintaining/running applications and (2) costs for developing and maintaining/running interfaces. Figure 1 (Winter, 2003b) illustrates this tradeoff. Due to network effects, we expect a nonlinear growth of the costs for applications and interfaces.

In real-life situations, the optimal degree of integration cannot be determined analytically because the costs are not constant and often they cannot be assigned directly to certain applications or interfaces. Therefore, instruments are needed which control and manage the evolution of an application architecture towards an approximated 'optimal' degree of integration. An evolutionary approach (i.e. a bundle of IS projects that improve the degree of integration successively) is needed because normally a revolutionary redesign of application architecture is not feasible due to immense costs. In order to measure the contribution of proposed projects towards the degree of integration, it is necessary to define objectives and derive performance indicators. In the next section, success factors for application integration are analyzed.

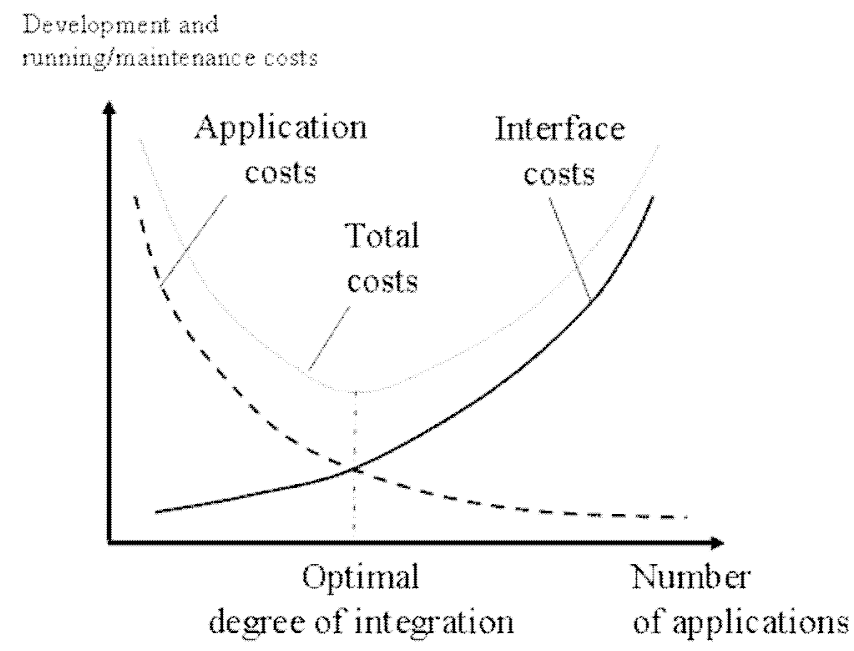

Figure 1. Application vs. interface costs tradeoff (Winter, 2005).

\section{SUCCESS FACTORS FOR APPLICATION INTEGRATION}

Numerous approaches to application integration can be found in the literature, many of them in the field of Enterprise Application Integration (EAI). We analyzed not only scientific contributions, but also practitioner papers regarding the success factors mentioned. Table 1 summarizes the results. The following success factors were mentioned most often:

- Minimal project expenses (time and costs) for integrating applications into the present application architecture.

- Optimal reuse of software components and minimal functional redundancy.

- Reduction of complexity within the present application architecture.

- Optimal coupling of applications (not tighter than needed, not looser than necessary).

- Minimal costs for and number of infrastructure components (e.g. middleware components like message broker or object request broker (ORB)).

Assuming that all these factors affect information systems performance, we propose one central figure which is analyzed in the upcoming sections: The agility of an information system. Agility is defined as the ability to react on upcoming changes effectively and efficiently (Ambrose and Morello, 2004). The main goal of application architecture (re-)design is to increase information systems' agility. The following sections intend to identify indicators which influence information systems' agility. Beside this proposed central success factor, many other criterions are conceivable, e.g. higher customer satisfaction by application integration. In the following we concentrate on the agility of an information system, only. 
Related work mostly proposes general rules for application integration only, e.g. achieving cost savings by reducing the number of interfaces when using a bus architecture. Quantitative measurements and the derivation of specific performance indicators are usually not considered.

\begin{tabular}{|c|c|c|c|c|c|}
\hline $\begin{array}{c}\text { Approach (vertical) / } \\
\text { Success factor (horizontal) }\end{array}$ & 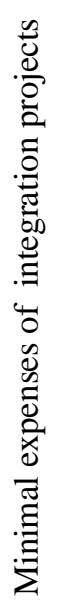 & 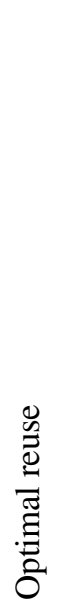 & 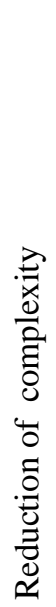 & 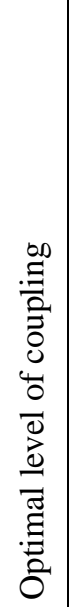 & 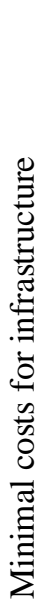 \\
\hline \multicolumn{6}{|l|}{ Scientific Contributions } \\
\hline (Linthicum, 2000) & & $\mathbf{X}$ & $\mathbf{X}$ & $\mathbf{X}$ & \\
\hline (Zahavi, 2000) & $\mathbf{X}$ & $\mathbf{X}$ & $\mathbf{X}$ & & $\mathbf{X}$ \\
\hline (Kaib, 2002) & $\mathbf{X}$ & $\mathbf{X}$ & $\mathbf{X}$ & $\mathbf{X}$ & $\mathbf{X}$ \\
\hline (Ruh, Maginnis and Brown, 2001) & $\mathbf{X}$ & $\mathbf{X}$ & $\mathbf{X}$ & $\mathbf{X}$ & $\mathbf{X}$ \\
\hline (Cummins, 2002) & $\mathbf{X}$ & $\mathbf{X}$ & $\mathbf{X}$ & $\mathbf{X}$ & $\mathbf{X}$ \\
\hline (Fridgen and Heinrich, 2004) & & & $\mathbf{X}$ & & $\mathbf{X}$ \\
\hline (Themistocleous and Irani, 2001) & $\mathbf{X}$ & $\mathbf{X}$ & & $\mathbf{X}$ & $\mathbf{X}$ \\
\hline \multicolumn{6}{|l|}{ Practitioner Approaches } \\
\hline (Liske, 2003) & $\mathbf{X}$ & & $\mathbf{X}$ & & \\
\hline (Moll, 2003) & $\mathbf{X}$ & & $\mathbf{X}$ & & $\mathbf{X}$ \\
\hline (Kuster and Schneider, 2003) & $\mathbf{X}$ & & $\mathbf{X}$ & $\mathbf{X}$ & $\mathbf{X}$ \\
\hline (Bath, 2003) & $\mathbf{X}$ & $\mathbf{X}$ & $\mathbf{X}$ & $\mathbf{X}$ & \\
\hline (Endries, 2003) & & & $\mathbf{X}$ & & $\mathbf{X}$ \\
\hline (Gröger, 2003) & $\mathbf{X}$ & $\mathbf{X}$ & $\mathbf{X}$ & & $\mathbf{X}$ \\
\hline (Knecht, 2003) & & $\mathbf{X}$ & & $\mathbf{X}$ & $\mathbf{X}$ \\
\hline (Hofer, 2003) & $\mathbf{X}$ & $\mathbf{X}$ & $\mathbf{X}$ & & \\
\hline (Friederich, 2003) & & $\mathbf{X}$ & $\mathbf{X}$ & & $\mathbf{X}$ \\
\hline (Aust, 2003) & $\mathbf{X}$ & & $\mathbf{X}$ & $\mathbf{X}$ & $\mathbf{X}$ \\
\hline
\end{tabular}

Table 1. Success factors for application integration in related work.

Figure 2 illustrates the identified success factors, the focus success factor "agility of the information system" and the assumed interdependencies between these success factors. In the following subsections, we describe and discuss the identified success factors in more detail and propose appropriate performance indicators. In Section 4, positive and negative interdependencies are analyzed in detail. 


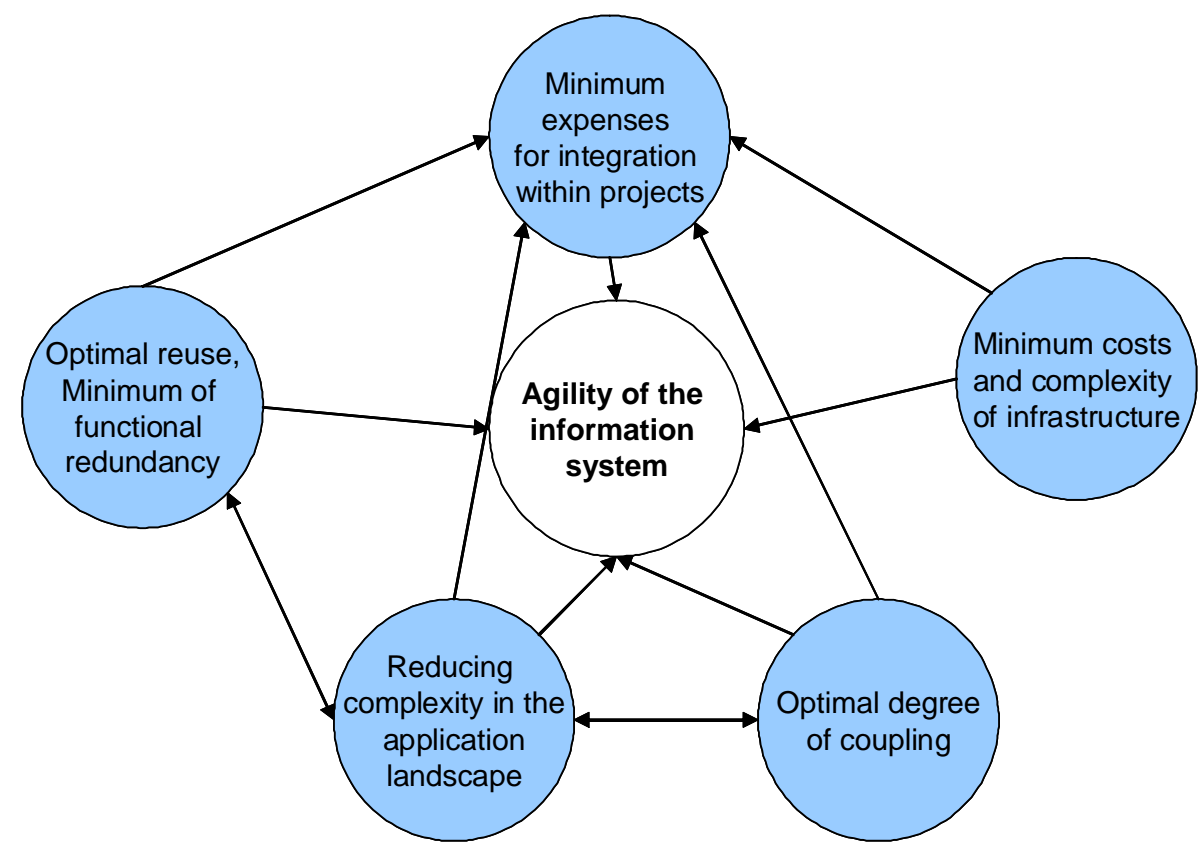

Figure 2. Application integration success factors and their interdependencies.

\section{Information systems' agility}

The agility of an information system expresses the ability to react on upcoming new or changed requirements (e.g. a new business function has to be supported). These requirements can be of technical nature (e.g. exchanging an application due to expired maintenance contracts), or they are triggered by business decisions (e.g. outsourcing decisions for certain business processes). Among the many factors that influence the agility of an information system, application architecture is of outstanding importance (Winter, 2003b). Until the end of the 1980ies, software development was dominated by creating monolithic applications in nearly all business areas-independent from the core competences of the company. A wide "information systemization" of all business processes was the main intention. After this first phase, the trend of implementing standard software packages (COTS, e.g. SAP R/3) came up. These packages provide a broad range of functionalities. The rapid growth and business importance of the internet triggered the addition of many more applications. In this phase, time to market was much more important than a sustainable and cost efficient application architecture. This led to redundancy as many functionalities got re-implemented, not integrated.

As a consequence of different application development phases with changing design goals, companies now struggle with an application architecture where functional silos, standardized packages and non-integrated internet applications coexist. In order to increase consistency and reduce operations costs, most companies run evolutionary application redesign programs.

In addition, new business requirements trigger new applications that lead to even more integration efforts. A survey by the Gartner Group reveals that $30 \%$ of the expenses in the software development process are needed to integrate (designing and implementing interfaces) software components. Another survey by the Gartner Group shows that about $40 \%$ of the ITBudgets are spent for implementing and maintaining interfaces (Krallmann, 2003).

The direct influence of the application architecture on the agility of the information system cannot be specified easily. A measurable coherence between the complexity of the inter-application relations and the agility would be a precondition.

In general, however, agility is measurable. The idea is to measure all extensions and changes to the information systems in a certain period $(\mathrm{C})$ and compare this to the total expenses needed for the extensions and changes (E). If two periods are compared, it can be checked whether extensions and changes have been implemented more efficiently. The comparison however cannot be carried out on a project-by-project basis because architecture management is a long-termed effort on an aggregate scale: "You Can’t 'Cost-Justify’ Architecture” (Zachman, 2001). 
As the figures $\mathrm{C}$ and $\mathrm{E}$ cannot usually provided directly from IT controlling, we propose figures for each success factor in the following.

\section{Application Architecture Complexity}

Historically grown application architectures comprising hundreds of applications (Linthicum, 2000) cannot be managed as a whole. The complexity is too high and the dependencies are too multifaceted. Therefore, it is necessary to control the complexity by knowingly des-integrating the application architecture. In our context, complex means that it is difficult to describe the behavior of the whole application architecture in any language even if we have detailed knowledge about each single application. To reduce the complexity, the application architecture can be spilt up into smaller defined components (building blocks). Among those components we propose loose coupling, within the components tight coupling. Loose coupling reduces dependencies among the components. That means that changes in one component will not affect the other component (Linthicum, 2000).

One way to des-integrate the application architecture is to define application domains which comprise a defined set of applications (e.g. the applications of one business unit (Schwinn and Hagen, 2005)). The number of application domains should be small to keep the advantage of lower complexity. In a concrete case in the financial service sector, the number of domains is about 20 (Schwinn and Hagen, 2005). It is important that applications within a domain can be modified without direct effects to other domains.

The most important figure is the degree of des-integration. To measure this figure, the number of loosely coupled controlled links (i.e. links that are directly controlled by architecture management) between application domains is counted. This figure has to be put in relation with the uncontrolled links between the domains. The quotient represents the level of des-integration.

To measure these figures, existing tools like source code analyzers or application repository managers can be used.

\section{Degree of Coupling}

General rules for the degree of coupling are not useful because each application relation is different. Intuitively, tight coupling is appropriate if two applications implement functionalities that belong to the same business process. If two applications implement functionalities of different business processes, loose coupling would be appropriate. The degree of coupling has direct influence on the agility of the information system: Tighter coupling necessarily will result in excess expenses for implementing new or changing existing requirements. If applications are coupled too loosely, runtime overhead may arise and additional middleware components for integration might be needed.

For each application relation, an appropriate level of coupling has to be chosen. Since a common methodology with objective criteria does not exist, it is difficult to derive measurable figures. A potential indicator could be the expenses for implementing changes in "dependent" applications due to modifications of an "independent" application. High expenses indicate too tight coupling. On the other hand, the runtime overhead has to be measured. A high runtime overhead would indicate too loose coupling. However it is difficult to exactly determine the runtime overhead. It usually cannot be measured directly because it is hidden in other maintenance or infrastructure costs. Even if the runtime overhead could be measured, the interpretation of measured values is difficult as no benchmarks exist.

As a consequence, a random sampling of applications and measurement of modification costs "induced" by context changes seem to be the only way to approximate the degree of coupling.

\section{Ruse / Functional Redundancy}

The success factor "optimal reuse" claims that every function is only implemented once by an application. If a function only has to be developed and maintained once, lower development and maintenance costs should be achievable. Furthermore, reuse supports the consistency, the quality and the flexibility of applications (Cummins, 2002). To achieve a maximum reuse, powerful middleware is needed to deliver the centrally implemented functionality to as many other applications as possible which are running on different platforms. In the design process, a framework is needed to ensure the future reusability of a component (Design-for-Reuse). One important aspect is the granularity of the function. If only large monolithic software components are developed, the potential for reuse is high because a broad functionality or parts of it can be reused. On the other side, dependencies are created, as the frequency of changes is higher and release cycles are shorter. If the components are too modular, the benefit of the reuse is lower and runtime and maintenance overhead increases because many small functions have to be reused-not only one. 
Another aspect that should be considered when designing reusable software components is the level of specialization. If only very specialized components are developed, the potential for reuse is low because only few applications or users need this very specialized function. Are the components too general, the potential for reuse should generally be higher, but the benefit for the "re-user" is low as only a very general service can be utilized. Furthermore, additional business logic has to be implemented by the "re-user" which leads to redundancy again. An example could be a service which checks the account balance of a customer of a bank. One function/service could be GetBalanceCustomerX() which is designated to one special customer X and therefore is very special. A very general service would be QueryDatabase(DatabaseName, Query). The potential for reuse of this service would be very high as many applications have to access databases. Considering our example, the benefit of this service is pretty low as we still have to adapt the service so that it returns the account balance of customer X. Obviously a service like GetBalance(Customer) would satisfy most needs. This example illustrates that it is very important to consider the level of specialization when designing new reusable functions or services.

For measuring reuse, one important figure is the average reuse per function which means how many applications actually use a certain function. To measure this figure, repositories are necessary which document the utilization of functions by applications. If there is a central server (e.g. a Corba server), it could be analyzed which applications are using which service.

Another important indicator for the quality of the application architecture is the number and growth of public interfaces. A high amount and a quick growth could indicate redundancy as we believe all functionality should be covered by reusable functions at a time. But fast growth could also be the result of introducing new technologies (e.g. service-oriented architecture). If so, the figure indicates the user acceptance of the new technology.

\section{Integration Project Expenses}

It is problematic to determine integration costs on a general level because integration effort is not only dependent on business requirements (e.g. timeliness) and technology support, but also on time. For example, the first project which uses a Corba infrastructure has to pay for the infrastructure while the following projects can re-use it, thereby receiving indirect sponsorship by the initial project. Furthermore, an isolated application which only has some relations to other applications usually has lower integration costs than an application which needs information und functions of many other applications (e.g. a portal application). As a consequence of these problems, we do not consider single projects, but entire project portfolios over a certain period to measure integration expenses.

Implications to the quality of integration aspects within the application architecture can only be drawn if the integration problem and the expenses are normalized. The integration costs depend on many factors (e.g. number of interfaces, number of business units involved, quality of existing documentation, etc.) which are hard to determine. As it is very hard to measure the integration complexity, we propose an indicator which compares the entirety of integration efforts: We sum up all integration costs and divide them by the overall integration complexity within a certain period (e.g. one year). If we compare two periods by dividing the quotient from the first year by the quotient of the second year, the result should be smaller than 1 . That means that we have implemented more integration complexity with lower expenses.

The only thing we can derive from this figure is the cost efficiency. However, without benchmarks we cannot determine useful target values.

\section{Costs and Complexity of the Integration Infrastructure}

The number of deployed integration technologies or tools within a company has direct influence on the fixed IT expenditures. As a consequence, the number of utilized tools has an (indirect) influence on IT project costs. If only a few tools are used, they can be supported professionally. Higher numbers of tools lead to uncertainties as developers have to decide which tool is most appropriate for specific requirements. On the other hand, a basic set of technologies is necessary to implement the requirements efficiently and to avoid workarounds by simulating one technology by means of another (e.g. using a message broker to implement a service-oriented architecture).

Possible figures for measuring this factor are infrastructure costs, number of deployed technologies and tools, standardization or the degree of fulfillment of project requirements by standard technologies and tools.

\section{SUCCESS FACTOR INTERDEPENDENCIES}

It seems likely that the identified success factors affect each other. Some of the success factors are complementary to each other, others are competing. In the following, all possible relations between success factors are analyzed. The derived hypotheses form a basis for further quantitative research. 


\section{Interdependencies between project expenses and reuse (see figure 3).}

Project expenses can be kept to a minimum if a large number of components are reusable. On the other hand, project expenses are usually higher if there are no reusable components and the project has to implement new components. Implementing a reusable component is expensive because efforts are needed which would not be needed if a single-use component is implemented (Boehm, Abts, Brown, Chulani, Clark, Horowitz, Madachy, Reifer and Steece, 2000; Ruh et al., 2001), mainly due to quality assurance reasons.

As we do not want to minimize short-term single project expenses, but instead want to minimize the total expenditures for the entire project portfolio over a long period, the influence of maximizing reusability should be positive. The savings should be higher than the additional expenses for developing reusable components. The earnings only can be realized when reusable components are actually reused. The more often a component is reused, the higher are the savings expected to be. But, the project costs will always have an initial effort to handle reusable components.

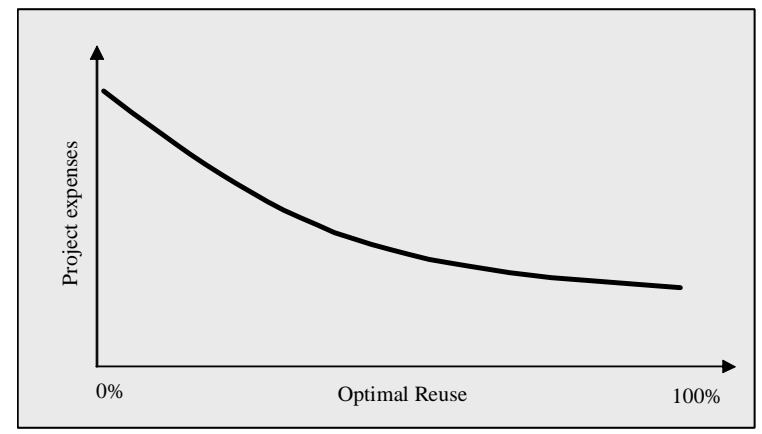

Figure 3.

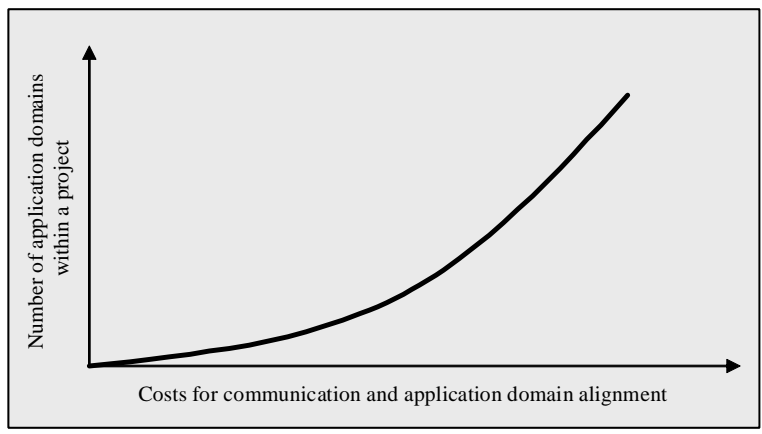

Figure 4.

\section{Interdependencies between project expenses and complexity (see figure 4).}

To minimize complexity, des-integration of the application architecture (e.g. by separating manageable application domains) has been proposed above. If development projects affect one application domain only, no specific complexity influence is present. If a development project affects more than one application domain, expenses are expected to increase. The more application domains are involved in a development project, the higher the communication costs are expected to be. Due to network effects, we expect a non-linear growth.

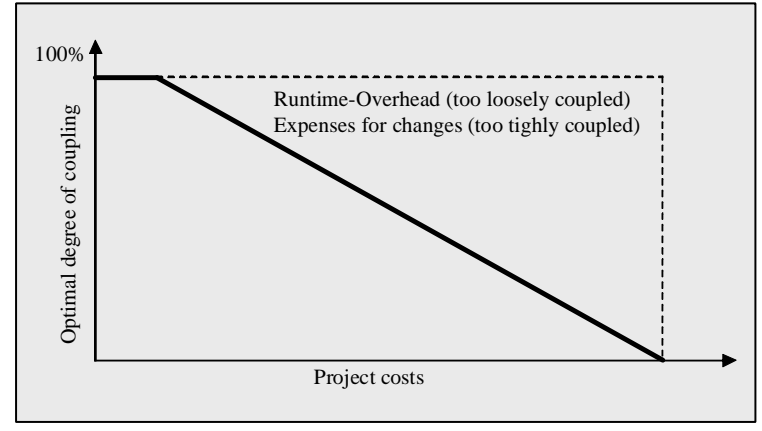

Figure 5.

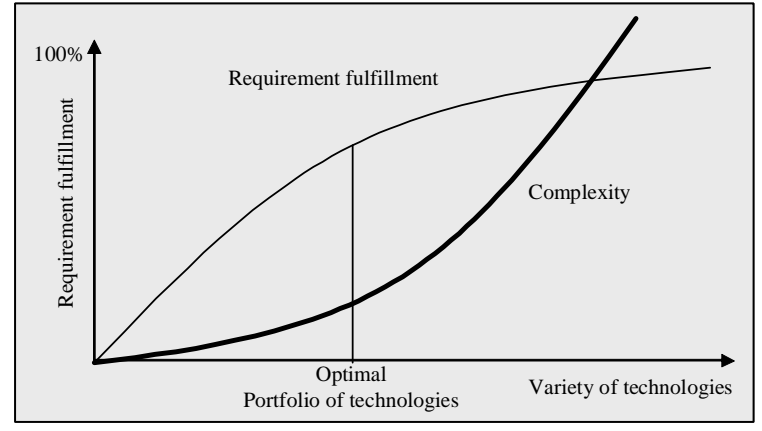

Figure 6. 
Interdependencies between project expenses and degree of coupling (see figure 5).

Optimal coupling claims to minimize dependencies among applications and to avoid the runtime overhead. The more appropriate the degree of coupling between applications is, the less development and runtime overhead may be expected (Linthicum, 2000). Both success factors are complementary to each other.

\section{Interdependencies between project expenses and costs / complexity of infrastructure (see figure 6).}

To reduce the costs and complexity of infrastructure, the number of deployed infrastructure components has to be restricted. This leads to a limitation of applicable technologies within a project (e.g. only Corba services are supported, web service technology is not used). The limitation of technologies incurs lower expenses for infrastructure, but they might not be able to meet project requirements perfectly. Therefore, additional project costs might be incurred to meet these requirements. Due to network effects, we expect a non-linear growth of the complexity as more and more technologies have to be compared against each other, whether they are appropriate within a project.

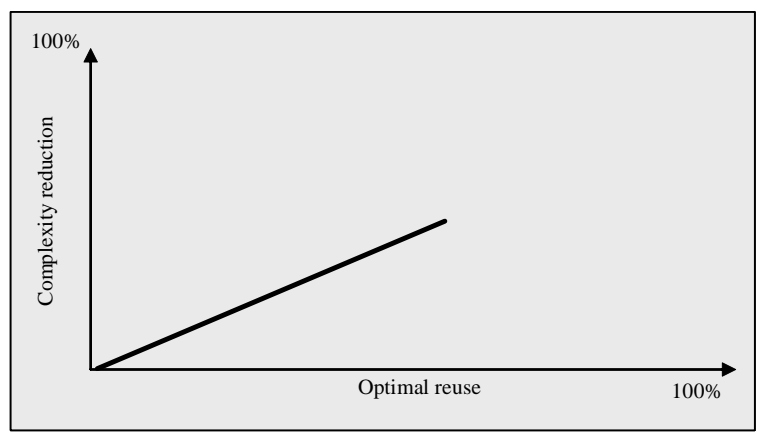

Figure 7.

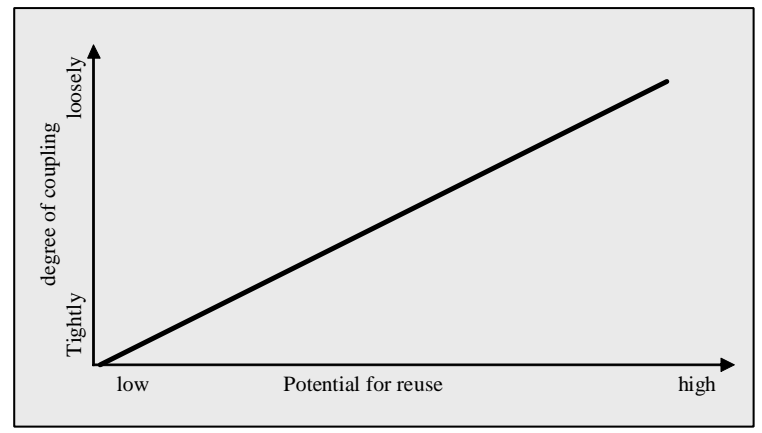

Figure 8.

\section{Interdependencies between reuse and complexity (see figure 7).}

Like for development projects, communication and alignment problems between application domains occur when implementing reusable components (used by different application domains). Choosing an appropriate granularity and generality of reusable components is essential. In general, implementing reusable components has a positive influence to the complexity (Ruh et al., 2001). However an optimal reuse does not imply a minimized complexity.

\section{Interdependencies between reuse and coupling (see figure 8).}

To realize a high potential of reuse, applications should be loosely coupled. A high potential of reuse means that one component may be used by many applications. If all applications are coupled tightly, the expenses for changing one component would be excessive. Tightly coupled components should therefore not be designed for reuse. Coupling of applications is necessary to reuse components (Kaib, 2002).

\section{Interdependencies between reuse and costs / complexity of infrastructure (see figure 9).}

If reusable components are developed independently from any technologies, these success factors do not influence each other. If however reusable components are developed using a certain technology, the number of technologies within a company obviously affects the reusability: For each reusable component, it has to be decided using which technology/ies the component should be developed (e.g. developing a Corba service or/and a web service). The larger the number of technologies is the more difficult are these decisions. Hence a positive influence among reusability and costs of infrastructure can be stated: the less technologies are deployed, the higher the potential for reuse (Kaib, 2002). Due to network effects, we expect a non-linear growth, as it gets harder and harder to make a decision (for which technology a component is developed). 


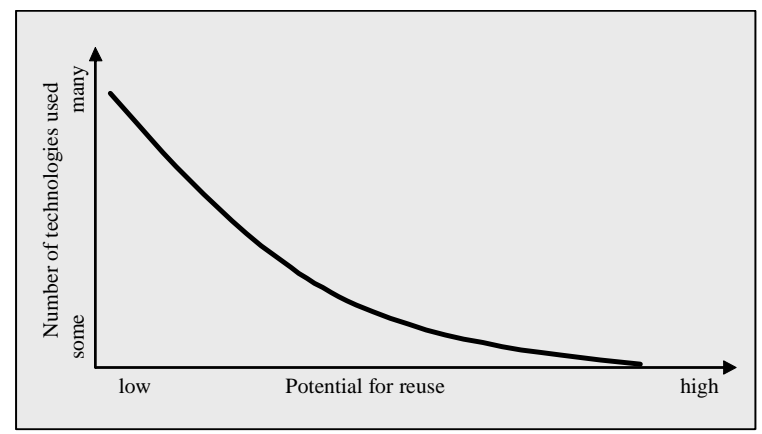

Figure 9.

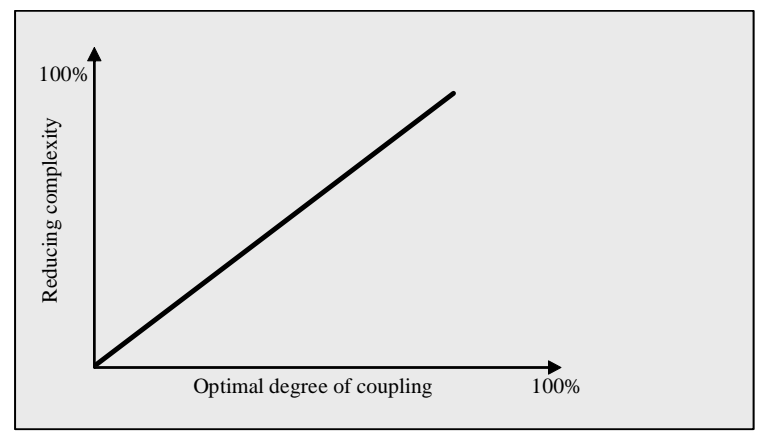

Figure 10.

\section{Interdependencies between complexity and coupling (see figure 10).}

Forming many application domains leads to many loosely coupled applications: Within application domains, a tight coupling dominates, but multi-domain applications are loosely coupled. If complexity is reduced, the influence on the degree of coupling is positive.

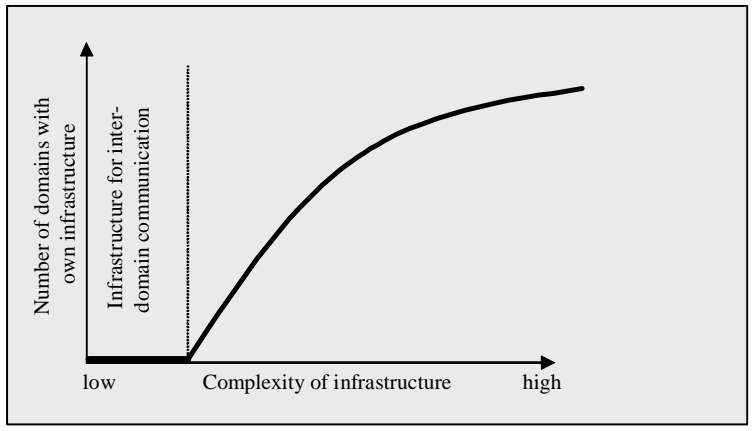

Figure 11.

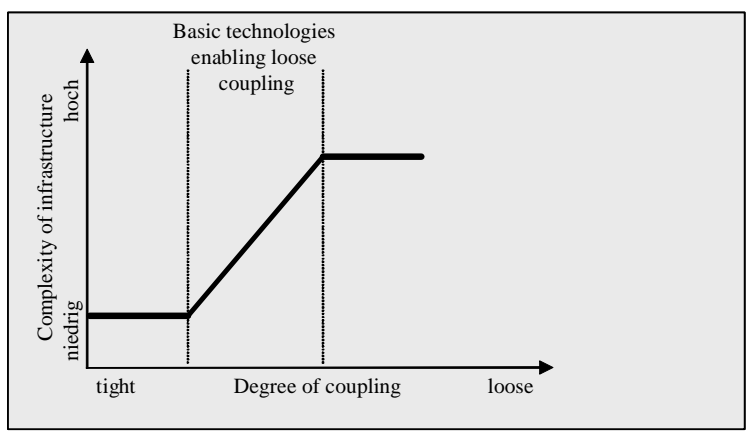

Figure 12.

\section{Interdependencies between complexity and costs / complexity of infrastructure (see figure 11).}

If the infrastructure is managed centrally (i.e. independently from application domains), both success factors do not influence each other. If the infrastructure is managed for every application domain separately, the expenses and the complexity grow non-linear with every managed application domain. Moreover, a centrally managed infrastructure is needed anyway for supporting inter-domain communication.

Interdependencies between coupling and costs / complexity of infrastructure (see figure 12).

If all applications are coupled tightly, infrastructure costs tend to be low as the applications do not have to communicate via middleware. If, in contrast, applications are coupled loosely, the "distance" between two applications has to be bridged. As a consequence, middleware is needed e.g. for transport, transformation, routing, etc. Since usually some loosely coupled applications exist in every application architecture, a standard set of middleware is needed anyway. If a set of middleware components is already available, the infrastructure costs and complexity do not grow further.

\section{CONCLUSIONS}

Based on a literature review and an analysis of current practices in companies, five success factors for application integration were proposed. For each success factor, performance indicators were discussed. Furthermore, the interdependencies among success factors have been analyzed qualitatively. Both aspects are essential to derive hypotheses which can be used to manage and control the application architecture systematically. 
The significance of the proposed success factors and their influence on the agility of an information system have been thoroughly discussed. However, neither the completeness of the proposed system of success factors nor the hypotheses for their interdependencies have been validated quantitatively. Both aspects are subject to further research.

\section{REFERENCES}

1. Ambrose, C. and Morello, D. (2004) Designing the Agile Organization: Design Principles and Practices, Gartner Group, ID Number: R-21-7532.

2. Aust, H. (2003) Einführung von EAI bei der PostFinance, 12. St. Galler Anwenderforum, St. Gallen.

3. Bath, U. (2003) Web Services als Teil einer serviceorientierten Architektur, EAI Forum Schweiz, Regensdorf.

4. Boehm, B., Abts, C., Brown, A. W., Chulani, S., Clark, B. K., Horowitz, E., Madachy, R., Reifer, D. and Steece, B. (2000) Software Cost Estimation with Cocomo II, Prentice Hall, New Jersey.

5. Cummins, F. A. (2002) Enterprise Integration, John Wiley \& Sons Inc., New York, et al.

6. Endries, T. (2003) Schenker AG-EAI, Integration Management Day, St. Gallen.

7. Fridgen, M. and Heinrich, B. (2004) Investitionen in die unternehmensweite Anwendungssystemintegration-Der Einfluss der Kundenzentrierung auf die Gestaltung der Anwendungslandschaft, Working Paper, Augsburg.

8. Friederich, M. (2003) Zusammenspiel verschiedener Integrationstechnologien und -werkzeuge bei der Züricher Kantonalbank, EAI Forum Schweiz, Regensdorf.

9. Gröger, S. (2003) Enterprise Application Integration in the Financial Services Industry. Integration Management Day, St. Gallen.

10. Hofer, A. (2003) Projekt SBB CUS: EAI ermöglicht eine Erhöhung der Kundeninformations-Qualität im öffentlichen Verkehr, 12. St. Galler Anwenderforum, St. Gallen.

11. Kaib, M. (2002) Enterprise Application Integration-Grundlagen, Integrationsprodukte, Anwendungsbeispiele, DUV, Wiesbaden.

12. Knecht, R. (2003) Application Architecture Framework UBS-WMBB, Integration Management Day, St. Gallen.

13. Krallmann, H. (2003) Transformation einer industriell geprägten Unternehmensstruktur zur einer service-orientierten Organisation, in Proceedings des Symposiums des Instituts für Wirtschaftsinformatik "Herausforderungen der Wirtschaftsinformatik in der Informationsgesellschaft", 1-12.

14. Krcmar, H. (1990) Bedeutung und Ziele von Informationssystemarchitekturen, Wirtschaftsinformatik, 32, 5, 395-402.

15. Kuster, S. and Schneider, M. (2003) Banking Bus EAI-Plattform der Raiffeisengruppe Schweiz, Integration Management Day, St. Gallen.

16. Linthicum, D. S. (2000) Enterprise Application Integration, Addison-Wesley, Reading, Massachusetts.

17. Liske, C. (2003) Advanced Supply Chain Collaboration enabled bei EAI, 12 St. Galler Anwenderforum, St. Gallen.

18. Malhotra, Y. (1996) Enterprise Architecture: An Overview, @BRINT Research Institute, http://www.brint.com/papers/enterarch.htm.

19. Martin, R. and Robertson, E. (2000) A Formal Enterprise Architecture Framework to Support Multi-model Analysis, in Proceedings of the 5th CAiSE/IFIP8.1 international workshop on evaluation of modeling methods in systems analysis and design, Stockholm.

20. McDavid, D. W. (1999) A standard for business architecture description, IBM Systems Journal, 38, 1, 12-31.

21. Moll, T. (2003) Firmenübergreifendes EAI-Netzwerk-Integrierte Umsetzung von Geschäftsprozessen über einen Marktplatz als EAI-Hub, Integration Management Day, St. Gallen.

22. Österle, H., Brenner, W. and Hilbers, K. (1992) Unternehmensführung und Informationssystem—Der Ansatz des St. Galler Informationssystem-Managements, Teubner, Stuttgart.

23. Ruh, W. A., Maginnis, F. X. and Brown, W. J. (2001) Enterprise Application Integration, John Wiley \& Sons Inc., New York et al.

24. Schwinn, A. and Hagen, C. (2005) Measured Integration-Metriken für die Integrationsarchitektur, in Schelp, J. and Winter, R. (Eds.) Integrationsmanagement, Springer, Berlin et al., forthcoming. 
25. Themistocleous, M. and Irani, Z. (2001) Benchmarking the benefits and barriers of application integration, Journal of Benchmarking, 8, 4, 317-331.

26. Winter, R. (2003a) Modelle, Techniken und Werkzeuge im Business Engineering, in Österle, H. and Winter, R. (Eds.) Business Engineering-Auf dem Weg zum Unternehmen des Informationszeitalters, Springer, Berlin et al., 87-118.

27. Winter, R. (2003b) An Architecture Model for Supporting Application Integration Decisions, in Ciborra, C. et al. (Eds.): Proceedings of 11th European Conference on Information Systems (ECIS), Naples.

28. Winter, R. (2005) Ein Modell zur Visualisierung der Anwendungslandschaft als Grundlage der InformationssystemArchitekturplanung, in: Schelp, J. and Winter, R. (Eds.) Integrationsmanagement, Springer, Berlin et al., forthcoming.

29. Youngs, R., Redmond-Pyle, D., Spass, P. and Kahan, E. (1999) A standard for architecture description, IBM Systems Journal, 38, 1, 32-50.

30. Zachman, J. A. (1987) A Framework for Information Systems Architecture, IBM Systems Journal, 26, 3, 276-292.

31. Zachman, J. A. (2001) You Can't 'Cost-Justify' Architecture, DataToKnowledge Newsletter (Business Rule Solutions LLC), 29, 3.

32. Zahavi, R. (2000) Enterprise Application Integration with CORBA, John Wiley \& Sons, New York et al. 